\title{
The role of plastic surgeons in extremity reconstruction following mass casualty incidents
}

\author{
Dustin T. Crystal, Ahmed M. S. Ibrahim, Samuel J. Lin \\ Division of Plastic Surgery, Beth Israel Deaconess Medical Center, Harvard Medical School, Boston, MA 02215, USA.
}

Correspondence to: Dr. Samuel J. Lin, Division of Plastic Surgery, Beth Israel Deaconess Medical Center, Harvard Medical School, 110 Francis Street Suite 5A, Boston, MA 02215, USA. E-mail: sjlin@bidmc.harvard.edu

How to cite this article: Crystal DT, Ibrahim AMS, Lin SJ. The role of plastic surgeons in extremity reconstruction following mass casualty incidents. Plast Aesthet Res 2019;6:1. http://dx.doi.org/10.20517/2347-9264.2018.69

Received: 26 Sep 2018 First Decision: 8 Oct 2018 Revised: 26 Nov 2018 Accepted: 8 Jan 2019 Published: 23 Jan 2019

Science Editor: Matthew L. Iorio Copy Editor: Cai-Hong Wang Production Editor: Huan-Liang Wu

\begin{abstract}
Aim: Mass casualty incidents ( $\mathrm{MCls}$ ) are a devastating source of morbidity and mortality, testing the infrastructure of acute care management and challenging the ability to reconstruct limbs. Herein, we look to further a discussion on upper and lower limb reconstruction following $\mathrm{MCls}$.
\end{abstract}

Methods: Review of the literature, including our institute's experience with the 2013 Boston Marathon Bombings, the 2015-2016 Terror Attacks in Ankara, and the 2010 earthquake in Haiti, pertaining to extremity reconstruction following $\mathrm{MCls}$.

Results: The three aforementioned case profiles highlight extremity wounds associated with $\mathrm{MCl}$ and the subsequent reconstructive role of plastic surgeons. Surgical intervention or temporization of extremity wounds is a critical responsibility of plastic surgeons in this setting. Limb salvage is possible and often the preferred option following disasters.

Conclusion: Intentional or naturally occurring $\mathrm{MCl}$ are a grim reality. Successful response to these events requires prompt mobilization of emergency medical staff and hospital activation. Plastic surgeons play a paramount role in multidisciplinary management of trauma with a particularly important involvement in limb reconstruction.

Keywords: Upper extremity reconstruction, lower extremity reconstruction, mass casualty incidents, microsurgery

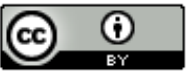

(C) The Author(s) 2019. Open Access This article is licensed under a Creative Commons Attribution 4.0 International License (https://creativecommons.org/licenses/by/4.0/), which permits unrestricted use, sharing, adaptation, distribution and reproduction in any medium or format, for any purpose, even commercially, as long as you give appropriate credit to the original author(s) and the source, provide a link to the Creative Commons license, and indicate if changes were made. 


\section{INTRODUCTION}

Initiated intentionally or as a result of natural disaster, mass casualty incidents (MCIs) continue to pose a significant challenge for emergency medical resources and multidisciplinary trauma teams. From earthquakes to landslides, geographical disasters frequently highlight multi-national relief efforts in resource constrained environments. In an era of domestic and international terrorism, deliberate episodes of mass violence utilizing explosives and firearms have disturbed the core of social intimacy and tested the resilience of regional care centers. Of particular concern in MCIs are crush and blast injuries to the upper and lower extremities, etiologies of which are rooted in the diversity of disaster types.

Specifically, the polytrauma associated with explosions results from a primary high-pressure blast wave and secondary discharge of fragmented projectiles causing injuries ranging from soft tissue loss to complete traumatic amputation ${ }^{[1,2]}$. In a clinical review of conflict and terrorist related trauma, Dussault et al ${ }^{[2]}$ found that on average, $54 \%$ of blast injuries affect the extremities. Similarly, a review by Clover et al. ${ }^{[3]}$ concluded that $60 \%$ of earthquake injuries are thought to localize to extremities, with $8 \%-13 \%$ associated with significant open fractures. The broad mechanisms of injury and bodily involvement seen within MCIs suggests an indispensable role for plastic surgeons in multidisciplinary teams comprised of colleagues from various specialties including orthopedic and trauma surgery ${ }^{[4]}$. As disasters become unfortunately more unexceptional, plastic surgeons need to prepare for and respond to civilian MCIs.

With the evolution of extremity reconstruction from skin grafts to local tissue rearrangements and microvascular free flap transfer, painstaking decisions regarding limb salvage efforts in MCIs must be determined by plastic surgeons. This concept is further influenced by resource constrains particular to the region where a disaster occurs. The purpose of this study is to highlight the various means of upper and lower limb reconstruction following MCIs.

\section{METHODS}

A review of the literature was performed using the following MEDLINE search terms: ("Limb Salvage"[Mesh] OR Extremity Reconstruct ${ }^{*}[$ tiab] OR "Surgery, Plastic"[MeSH] OR “Trauma Surgery"[Tiab] OR “Orthoplastic"[tiab]) AND (Mass Casualty[tiab] OR Terrorism[tiab] OR Earthquake[tiab] OR Blast Injur ${ }^{\star}[$ tiab] OR Explosion[tiab] OR Triage[tiab]). Titles and abstracts were screened for relevance. The initial search was limited to English-only articles and constrained to the past 30 years. Citations of assessed manuscripts were screened for applicable articles.

\section{RESULTS}

Three events including our institution's experience with the 2013 Boston Marathon Bombing, the 2015-2016 Ankara Terrorist Attacks, and the 2010 Earthquake in Haiti were specifically chosen to highlight extremity wounds associated with MCIs and the subsequent reconstructive role of plastic surgeons.

\section{Boston bombing}

On 15 Apr 2013, two pressure cooker bombs exploded along the route of the 117th Boston Marathon. The ground-level positioning and shrapnel components of the explosives lead to significant extremity trauma ${ }^{[5]}$. In total, $66 \%$ of admitted patients had lower extremity soft tissue and/or bony injuries ${ }^{[6]}$.

Our institution received 24 patients, 11 of whom were cared for by the plastic surgery service. All 11 patients had lower extremity injuries, while 4 had concomitant upper extremity injuries ${ }^{[7]}$. Wounds were grossly contaminated by foreign bodies, foreign tissue, and weaponized debris deliberately intended to inflict secondary damage on patients. Three patients required lower extremity flap reconstruction in the acute to subacute setting. 
The first patient presented with an open left fibula fracture, left medial and right posterior calf wounds, and a left thigh wound. After debridement and washout, the fibula fracture was reduced, and tissue reconstruction was performed with a local soleus muscle flap ${ }^{[7]}$. A second patient presented with a partial left lower extremity traumatic amputation, an open right tibia/fibula fracture, and several leg and buttock wounds. A completion left below-the-knee amputation and several washouts with debridement were necessary. After external fixation and negative pressure wound therapy, a free latissimus dorsi muscle flap and split thickness skin graft were used for right lower extremity reconstruction ${ }^{[7]}$. The third patient presented with an open left tibia/fibula fracture and non-viable left foot. Completion amputation and negative pressure wound therapy followed by revision amputation were performed. A local gastrocnemius flap with split thickness skin grafting was required for closure of the complex amputation defect ${ }^{[7]}$.

At our affiliate hospital, 13 patients required emergent surgery. Among those patients, 72 procedures would be completed, of which a remarkable $37 \%$ were performed by plastic surgery ${ }^{[8]}$. Moreover, nearly $50 \%$ of these emergent surgery patients required free flaps for limb salvage ${ }^{[8]}$. Among all receiving hospitals, 54 patients underwent emergent surgery and 12 patients underwent definitive amputation for control of life-threatening hemorrhage and/or severe, unsalvageable extremity wounds ${ }^{[6]}$.

\section{5-2016 terror attacks in Ankara, Turkey}

In a period of one year the capital city of Turkey, Ankara, was struck by two major terrorist attacks. On 10 Oct 2015, a suicide bomber detonated an explosive in Ankara's central railway station. This was followed on 13 Mar 2016 by a car bomb detonated during rush hour at Kizılay Square-Güvenpark. In total, there were 434 casualties, 178 of whom would receive care at Ankara Numune Training and Research Hospital, a tertiary health and trauma center within Ankara ${ }^{[9]}$.

Of the casualties received, $28 \%$ sustained an upper extremity injury and 50\% sustained a lower extremity injury ${ }^{[9]}$. A retrospective review was conducted on 34 victims who required surgical treatment by the plastic surgery service at Ankara Numune Hospital ${ }^{[9]}$. Of note, patients treated in the emergency department for minor injuries and small primary closures were not included in this review. In total, one patient required thumb replantation while an additional eight patients had hand surgery for phalynx fractures, flexor tendon repairs, and peripheral nerve injuries. One presenting patient required a local trapezius muscle flap for a shoulder soft tissue defect. Another required a free radial forearm fasciocutaneous flap for soft tissue trauma to the medial foot. Lastly, a third patient presented with a Gustilo IIIB fracture requiring a free anterolateral thigh fasciocutaneous flap for coverage of exposed tibia. Partial flap necrosis occurred, prompting salvage treatment by means of a cross-leg flap ${ }^{[9]}$.

Importantly, the authors highlight that the lack of plastic surgeons in their hospital trauma advisory council and their delayed consultation following the incidents were barriers to providing services. Although no amputations were reported in their cohort, the surgeons note that amputations were performed prior to consultation.

\section{0 earthquake in Haiti}

On January 12, 2010, a 7.0-magnitude earthquake struck the nation of Haiti. In an already resource constrained nation, the humanitarian crisis which followed was of mass proportion. Part of the relief experience was captured by a responding British orthoplastic envoy ${ }^{[10]}$. Similar to experiences documented from a 7.4-magnitude earthquake in Turkey ${ }^{[11]}$, the predominant injury received by the surgical team were extremity crush injuries ${ }^{[10]}$.

In total, 348 operations were performed by the orthoplastic limb salvage team on 158 patients. The $73 \%$ of procedures were of soft-tissue origin and performed by plastic surgeons, while $18 \%$ of procedures were of 
Table 1. Indications for amputation vs, limb salvage following mass casualty incidents

\begin{tabular}{|c|c|}
\hline Amputation & Limb salvage \\
\hline Life-threatening hemorrhage or refractory hypotension & Minimal-to-no distal sensation, peripheral nerve disruption ${ }^{[13]}$ \\
\hline $\begin{array}{l}\text { Warm lower limb and upper limb ischemia for }>6 \text { or }>8 \mathrm{~h} \text {, } \\
\text { respectively }{ }^{[49]}\end{array}$ & Stable distal extremity vascular assessment \\
\hline $\begin{array}{l}\text { Severe partial traumatic amputation and/or multi-level soft tissue, } \\
\text { osseous, and vascular defects }\end{array}$ & $\begin{array}{l}\text { Limited access to prosthesis centers or limited potential for rehabilitation in } \\
\text { the patient (i.e., access or functional capacity) })^{[50]}\end{array}$ \\
\hline Resource and infrastructure constraints & Viable, non-injured donor sites for tissue transfer \\
\hline
\end{tabular}

Uniformly: patient preference, age, and comorbidities should be considered

bony and soft-tissue origin necessitating joint orthoplastic involvement ${ }^{[10]}$. The most frequently performed procedures included wound dressing changes, surgical debridements, and split thickness skin grafts. Notably, $10 \%$ of patients received pedicled flaps for local reconstruction and coverage of exposed bone, as free flaps were technically impossible within the field hospital ${ }^{[10]}$. Ultimately, there were six amputations in this series, three below-the-knee, one above-the-knee, and two digital amputations. Of these amputations, only two were in cases of failed limb salvage ${ }^{[10]}$.

\section{DISCUSSION}

The aforementioned case profiles highlight the significant reality that MCIs are an ever-possible occurrence in our society. Of particular concern is the high prevalence of extremity wounds following disasters such as earthquakes or bombings ${ }^{[2,3]}$. Subsequent decisions regarding limb salvage in this setting are complex and are impaired by resource availability [Table 1].

Following resuscitation, early assessment of distal neurovascular stability is critical to appraise the utility of reconstruction [Figure 1]. Vascular assessment and doppler ultrasound interrogation should be performed prior to considering CT-angiography. As evidenced by reports from French terror attacks, peripheral nerve injuries are common in $\mathrm{MCIs}^{[12]}$, however they do not definitively preclude reconstruction. Data from the Lower Extremity Assessment Project (LEAP) challenged historical beliefs that a lack of plantar sensation is an indicator for amputation. The authors found that those with insensate lower limbs who underwent reconstruction had proportionally similar plantar sensation on testing at two years when compared to those who had intact plantar sensation prior to reconstruction ${ }^{[13]}$. Adding complexity to the situation, delayed access to patients at the location of disasters interrupts transport and evaluation and lengthens ischemia time, thereby increasing risk of compartment syndrome and rates of amputation ${ }^{[6,14]}$.

As our case profiles depict, amputation in the setting of MCIs should be reserved for those with life threatening hemorrhage and severe wounds beyond that of conceivable reconstruction. Further complicating decisions of mangled extremity limb salvage, a prospective study from the LEAP found that no single extremity trauma scoring system can effectively guide amputation decisions ${ }^{[15]}$. The limiting factors for salvage in the described MCIs were patient stability, wound severity, and resource availability. Life-saving amputations must be made definitively, however, as noted at the Bégin Military Teaching Hospital following terror attacks in Paris, stable amputations should always involve discussion with the patient ${ }^{[16]}$.

The utility and quality of life following amputation is subject to significant debate when compared to reconstruction. A large prospective series by Bosse et al. ${ }^{[17]}$ identified similar self-reported functional outcomes at two years between those who underwent amputation or lower extremity reconstruction. Comparatively, a 2008 systematic review reported that the mean percentage of patients returning to work was higher in those who received amputation compared to reconstruction ${ }^{[18]}$. More recently, cost-utility analyses of lower extremity trauma found that amputation was significantly more expensive ${ }^{[19]}$, and yielded slightly less quality-adjusted life years ${ }^{[19]}$, when compared to reconstruction. 


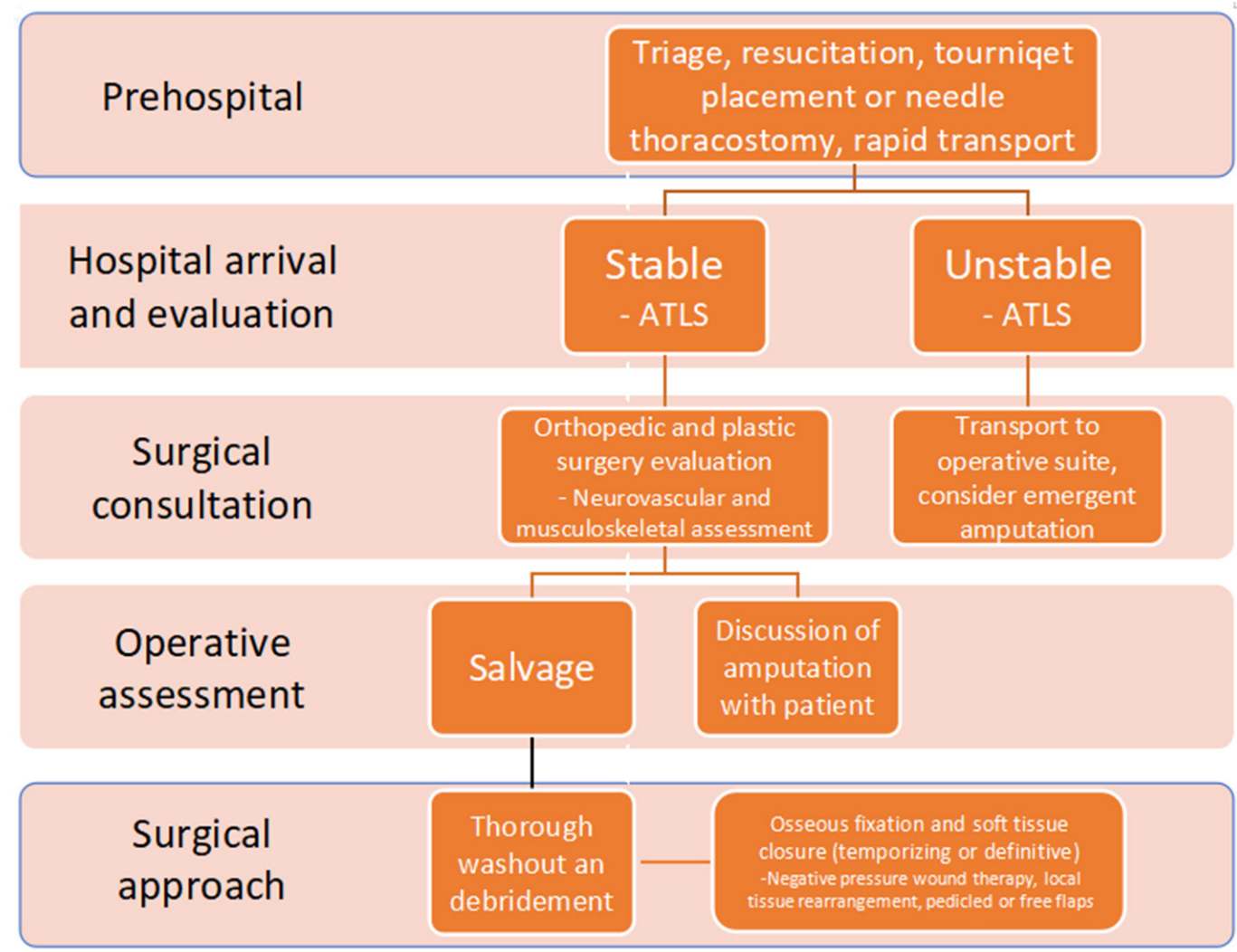

Figure 1. Approaches to triage and patient management following mass casualty incidents. ATLS: advanced trauma life support

The discussion is considerably more germane in resource constrained regions where rehabilitation services and prosthetics are extremely costly and often unavailable. A review on land mine induced lower extremity injuries in developing countries highlights poor post-amputation outcomes associated with a significant inability to access rehabilitation, return to work, and provide for families ${ }^{[20]}$. With post-earthquake amputation rates around $6 \%{ }^{[21]}$, deployment of salvage teams helps curtail such significant societal losses.

This guides conversation towards the importance of limb salvage. Ideal extremity trauma reconstruction aims to obtain soft-tissue coverage, restore appropriate form, and maintain or improve function ${ }^{[22]}$. In the acute to subacute setting of MCIs, the feasibility of reconstruction is challenged. As numerous patients present with contamination and injuries to several body zones, a balance between otherwise reliable local tissue rearrangements and their complex free flap alternatives must be achieved.

Following the Boston Bombings, our institution utilized both local and free flaps for extremity reconstruction. Playing a fundamental role in early soft tissue closure, local flaps are associated with shorter procedure times, reduced complexity, and are of similar tissue quality and color to that of the recipient site $^{[23]}$. Based on a pedicle, local flaps offer considerable adaptability with tailored thinning and a rotational advantage. Moreover, as depicted from experience following the 2015 Earthquake in Haiti, local flap coverage can be performed in field hospitals lacking the infrastructure necessary for free flap microsurgery ${ }^{[10]}$. With a significant influx of patients, the use of local flaps effectively allows for durable soft tissue coverage in the acute to subacute period providing an equitable distribution of services to patients.

With the high incidence of hand injuries following MCIs, there is particular utility in local reconstructive flaps including V-Y advancement flaps for dorsal fingertip reconstruction, the dorsal metacarpal artery flap for thumb reconstruction, and cross-finger transposition flaps ${ }^{[24]}$. Local forearm and elbow reconstruction 
can be performed with a pedicled radial forearm flap (RFF) or lateral arm flap (LAF). Supplied by a long vascular pedicle from the anterograde radial artery or retrograde palmar arch, the adipofascial to fasciocutaneous RFF is considerably resourceful. With traumatic elbow injuries often exposing bone, tendon, or neurovasculature, the RFF and LAF can effectively resurface the thin yet tenacious native tissue $^{[25]}$. Although the latissimus dorsi muscle flap (LDF) is a more sizeable regional alternative for elbow reconstruction, Choudry et al. ${ }^{[25]}$ showed increased rates of flap failure when pedicled LDFs were compared to pedicled RFFs or local fasciocutaneous flaps for elbow reconstruction. Moreover, RFFs and LAFs can be harvested as composites, with radial or humeral bone grafts and/or tendon for complex defects. Sacrifice of the radial artery in RFFs must be considered, however there appears to be minimal patient-reported hand function impairment, independent of donor site closure strategy ${ }^{[26]}$. In proximal arm and shoulder trauma, local tissue advancements and scapular or parascapular flaps are readily applied. A trapezius flap was utilized to reconstruct a shoulder defect following the Ankara bombings ${ }^{[9]}$. As a pedicle supplied by the dorsal scapular artery, this approach has minimal reported donor site morbidity ${ }^{[27]}$. Based on the thoracodorsal artery, the pedicled LDF provides a well vascularized muscle to fasciocutaneous flap employed for proximal upper extremity and axillary soft tissue defects ${ }^{[28,29]}$. The use of functional, pedicled LDFs have been described to restore upper arm strength and function following reconstruction with considerable success $^{[28,30]}$. This said, a systematic review assessing donor site morbidity highlighted several publications which report symptomatic shoulder strength limitations following latissimus dorsi transfer, partly reduced by muscle sparing and perforator based approaches ${ }^{[29]}$.

With regard to lower extremity reconstruction, conventional practice suggests use of gastrocnemius and soleus flaps for coverage of injuries at the proximal and middle thirds of the leg, respectively ${ }^{[31]}$. The complication rates of these local flaps are often cited as minimal; however, studies have identified a quantifiable decrease in donor limb strength following reconstruction ${ }^{[32]}$. Representative claims of such nature are often challenging to quantify as the untrialed alternative is recipient limb amputation. Subsequently, in our series, a soleus muscle flap was employed for tissue closure while another patient required a gastrocnemius muscle flap for amputation site closure without complication ${ }^{[7]}$. Additional local flaps, such as the innervated sural flap and reverse hemisoleus flap, have been described for reconstruction of the distal third of the leg and foot with good functional outcomes ${ }^{[2,33,34]}$. These distally oriented flaps are potential alternatives to free flap tissue transfer in resource constrained locations. Still, they are technically demanding local flaps - a victim of the November 2015 France terror attacks ultimately required secondary amputation after failure of a pedicled sural flap utilized for posterior ankle reconstruction ${ }^{[16]}$. A review by Follmar et al ${ }^{[35]}$ found that distally oriented sural flaps had complication rates of 50\%-59\%, with relatively high rates of venous congestion. Sugg et al. ${ }^{[33]}$ retrospectively identified similar complication rates, but prevented venous congestion by widening the flap pedicle. In contrast to the leg and foot, significant bulk and musculature of the thigh affords exceptional flexibility for local tissue rearrangements if not direct primary closure. Supported by the medial and lateral femoral circumflex arteries, the thigh provides reliable vasculature for local flaps and is an ideal donor site for free flap transfer.

Unfortunately, local flaps become less utile as traumatic wounds become more complex, involve composite defects, and occur more distally [Table 2]. In these situations, free flap transfer is preferred ${ }^{[31]}$. The robust anterolateral thigh flap (ALT) and previously described LDF and RFF serve as versatile approaches to upper and lower extremity reconstruction. Used in the Boston Bombings and Ankara Terrorist Attacks, these workhorse free flaps are dependable for large or distal defects seen after explosions or natural disasters. As a testament to their utility, several series on extremity free flap reconstruction have reported flap failure rates $<10 \%$ with few cases requiring secondary amputation ${ }^{[36,37]}$. Liberated from their pedicles, the LDF and RFF combine previously described advantages and limited donor site morbidity with a freedom of recipient site location and orientation. Notably, the ALT provides a tailored thickness fasciocutaneous or 


\begin{tabular}{|c|c|c|}
\hline & Local flaps & Free flaps \\
\hline \multirow[t]{4}{*}{ Advantages } & Reduced procedure time and less technically demanding ${ }^{[23]}$ & Superior diversity for donor and recipient site combinations \\
\hline & $\begin{array}{l}\text { Donor tissue is similar in characteristic to that of the } \\
\text { recipient site } \mathrm{e}^{[23]}\end{array}$ & Covering large, tridimensional soft tissue defects \\
\hline & Pedicle provides a reliable, durable, and native blood supply & Greater capacity for harvesting as composite or chimeric grafts \\
\hline & Can be performed under local anesthesia or conscious sedation & Preferred option in distal lower extremity reconstruction ${ }^{[31]}$ \\
\hline \multirow[t]{3}{*}{ Limitations } & Range of transfer is limited by pedicle length & Requires infrastructure and equipment to support microvascular surgery \\
\hline & $\begin{array}{l}\text { Extremity trauma may impact nearby tissue and preclude or } \\
\text { limit local rearrangements }\end{array}$ & $\begin{array}{l}\text { Higher risk of complication due to reliance on non-native } \\
\text { microvascular anastomosis }\end{array}$ \\
\hline & Less utile in composite tissue defects & Greater need for post-operative monitoring \\
\hline
\end{tabular}

musculocutaneous flap supplied by perforators of the descending branch of the lateral circumflex femoral artery. Its reliable dissection pattern affords a long pedicle, large tissue paddle, and minimal donor site morbidity, all of which are ideal for upper or lower limb reconstruction ${ }^{[24,38,39]}$. Thinning to $2-4 \mathrm{~mm}$ has safely been reported ${ }^{[39,40]}$. Further advantages of the ALT include an ability for innervation via the lateral femoral cutaneous nerve, offering improved recipient-site sensation, and options to co-harvest with the fascia lata for tendon reconstruction ${ }^{[38,39]}$. Moreover, in severe extremity trauma with noted recipient vessel damage, multidisciplinary teams of plastic and vascular surgeons can facilitate free flap techniques with concurrent arterial reconstructions, vascular bypass, or arteriovenous-loop formation ${ }^{[41]}$.

Current debate regarding the efficacy and outcomes of fasciocutaneous $v s$. muscle flaps for traumatic reconstruction is controversial. Conventional belief has assigned superiority to muscle flaps, particularly in large, tridimensional extremity defects with exposed bone and high risk of infection ${ }^{[42]}$. Recently, Stranix et al ${ }^{[43]}$ reported a 40 -year retrospective series in which fasciocutaneous flaps had statistically significant increased take-back rates but superior salvage rates compared to muscle flaps, owed largely to the cutaneous clinical monitoring of fasciocutaneous flaps. A retrospective series on traumatic upper and lower limb reconstruction in wounded warriors demonstrated no statistically significant differences in overall complication rate or days to ambulation among patients treated with muscle or fasciocutaneous flaps, but found that muscle flaps had statistically significant increased rates of flap failure ${ }^{[4]}$. However, a recent multicenter analysis reported comparable limb salvage rates of $90 \%$ and $88 \%$-94\% when muscle or fasciocutaneous flaps, respectively, were employed for lower extremity trauma reconstruction ${ }^{[45]}$.

There is considerable discussion regarding the appropriate timing of extremity reconstruction following trauma. Historically, advocates have suggested soft tissue coverage of extremity defects within 24-72 h of the initial trauma ${ }^{[46]}$. A more contemporary systematic review of upper extremity reconstruction found no statistically significant association between reconstruction timing and flap complications including infection, bony nonunion, and flap loss ${ }^{[22]}$. However, lending support for the original works of Marko Godina $^{[46]}$, an in-press systematic review of lower extremity reconstruction concluded that rates of flap loss and infection were lower in those who received soft tissue reconstruction within $72 \mathrm{~h}^{[47]}$. In our experience with the Boston bombings, flap reconstruction was performed in the acute to subacute time period. This is not always feasible, and experience from the 2015 Earthquake in Haiti demonstrated that negative pressure wound therapy was an invaluable adjunct to temporize and protect wounds until reconstructive specialists arrived and offered definitive tissue closure in the subacute period ${ }^{[48]}$.

In conclusion, we must acknowledge that the heterogenous nature of extremity wounds following MCIs remains a unique challenge for reconstructive surgeons. With the lack of high quality randomized prospective trials; clinical expertise, available resources, and patient presentation will continue to guide reconstructive decision making. 


\section{DECLARATIONS}

\section{Authors' contributions}

Conception and design, acquisition of data, or analysis and interpretation of data, approved the final version to be published, and agreed to be accountable for all aspects of the work in ensuring that questions related to the accuracy or integrity of any part of the work are appropriately investigated and resolved: Crystal DT, Ibrahim AMS, Lin SJ

Drafted the article: Crystal DT

Revised the article critically for important intellectual content: Ibrahim AMS, Lin SJ

\section{Availability of data and materials}

No overt datasets were generated or analyzed in this study.

\section{Financial support and sponsorship}

None.

\section{Conflicts of interest}

All authors declared that there are no conflicts of interest.

\section{Ethical approval and consent to participate}

Not applicable.

\section{Consent for publication}

Not applicable.

\section{Copyright}

(C) The Author(s) 2019.

\section{REFERENCES}

1. Peleg K, Aharonson-Daniel L, Michael M, Shapira SC; The Israel Trauma Group. Patterns of injury in hospitalized terrorist victims. Am J Emerg Med 2003;21:258-62.

2. Dussault MC, Smith M, Osselton D. Blast injury and the human skeleton: an important emerging aspect of conflict-related trauma. J Forensic Sci 2014;59:606-12.

3. Clover AJ, Jemec B, Redmond AD. The extent of soft tissue and musculoskeletal injuries after earthquakes; describing a role for reconstructive surgeons in an emergency response. World J Surg 2014;38:2543-50.

4. Thakar HJ, Pepe PE, Rohrich RJ. The role of the plastic surgeon in disaster relief. Plast Reconstr Surg 2009;124:975-81.

5. Kolata G, Longman J, Pilon M. Doctors saved lives, if not legs, in Boston. The New York Times April 16, 2013. Retrieved August 28, 2015. Available from: http:/www.nytimes.com/2013/04/17/us/physical-legacy-of-bomb-blasts-could-be-cruel-for-boston-marathonvictims.html. [Last accessed on 14 Jan 2019]

6. Gates JD, Arabian S, Biddinger P, Blansfield J, Burke P, et al. The initial response to the Boston marathon bombing. Ann Surg 2014;260:960-6.

7. Kim PS, Malin E, Kirkham JC, Helliwell LA, Ibrahim AM, et al. The Boston marathon bombings: the early plastic surgery experience of one Boston hospital. Plast Reconstr Surg 2013;132:1351-63.

8. Caterson EJ, Carty MJ, Weaver MJ, Holt EF. Boston bombings: a surgical view of lessons learned from combat casualty care and the applicability to Boston's terrorist attack. J Craniofac Surg 2013;24:1061-7.

9. İ̆ğde M, Kaplan A. Plastic surgery management of victims of terrorist violence in Ankara, Turkey. Ann Plast Surg 2017;79:600-5.

10. Clover AJ, Rannan-Eliya S, Saeed W, Buxton R, Majumder S, et al. Experience of an orthoplastic limb salvage team after the Haiti earthquake: analysis of caseload and early outcomes. Plast Reconstr Surg 2013;127:2373-80.

11. Wolf Y, Bar-Dayan Y, Mankuta D, Finestone A, Onn E, et al. An earthquake disaster in Turkey: assessment of the need for plastic surgery services in a crisis intervention field hospital. Plast Reconstr Surg 2001;107:163-8.

12. Gregory TM, Bihel T, Guigui P, Pierrart J, Bouyer B, et al. Terrorist attacks in Paris: surgical trauma experience in a referral center. Injury 2016;47:2122-6.

13. Bosse MJ, McCarthy ML, Jones AL, Webb LX, Sims SH, et al. The insensate foot following severe lower extremity trauma: an indication for amputation? J Bone Joint Surg Am 2005;87:2601-8. 
14. Chunguang Z, Rigao C, Fuguo H, Chongqi T, Yueming S, et al. Characteristics of crush syndrome caused by prolonged limb compression longer than $24 \mathrm{~h}$ in the Sichuan earthquake. Emerg Med J 2010;27:627-30.

15. Bosse MJ, MacKenzie EJ, Kellam JF, Burgess AR, Webb LX, et al. A prospective evaluation of the clinical utility of the lower-extremity injury-severity scores. J Bone Joint Surg Am 2001;83-A:3-14.

16. Barbier O, Malgras B, Choufani C, Bouchard A, Ollat D, et al. Surgical support during the terrorist attacks in Paris, November 13, 2015: experience at Bégin military teaching hospital. J Trauma Acute Care Surg 2017;82:1122-8.

17. Bosse MJ, MacKenzie EJ, Kellam JF, Burgess AR, Webb LX, et al. An analysis of outcomes of reconstruction or amputation after legthreatening injuries. N Engl J Med 2002;347:1924-31.

18. Saddawi-Konefka D, Kim HM, Chung KC. A systematic review of outcomes and complications of reconstruction and amputation for type IIIB and IIIC fractures of the tibia. Plast Reconstr Surg 2008;122:1796-805.

19. Chung KC, Saddawi-Konefka D, Haase SC, Kaul G. A cost-utility analysis of amputation versus salvage for Gustilo type IIIB and IIIC open tibial fractures. Plast Reconstr Surg 2009;124:1965-73.

20. Walsh NE, Walsh WS. Rehabilitation of landmine victims--the ultimate challenge. Bull World Health Organ 2003;81:665-70.

21. Yang C, Wang HY, Zhong HJ, Zhou L, Jiang DM, et al. The epidemiological analyses of trauma patients in Chongqing teaching hospitals following the Wenchuan earthquake. Injury 2009;40:488-92.

22. Harrison BL, Lakhiani C, Lee MR, Saint-Cyr M. Timing of traumatic upper extremity free flap reconstruction: a systematic review and progress report. Plast Reconstr Surg 2013;132:591-6.

23. Parrett BM, Talbot SG, Pribaz JJ, Lee BT. A review of local and regional flaps for distal leg reconstruction. J Reconstr Microsurg 2009;25:445-55.

24. Griffin M, Hindocha S, Malahias M, Saleh M, Juma A. Flap decisions and options in soft tissue coverage of the upper limb. Open Orthop J 2014;8:409-14.

25. Choudry UH, Moran SL, Li S, Khan S. Soft-tissue coverage of the elbow: an outcome analysis and reconstructive algorithm. Plast Reconstr Surg 2007;119:1852-7.

26. Ho T, Couch M, Carson K, Schimberg A, Manley K, et al. Radial forearm free flap donor site outcomes comparison by closure methods. Otolaryngol Head Neck Surg 2006;134:309-15.

27. Rasheed MZ, Tan BK, Tan KC. The extended lower trapezius flap for the reconstruction of shoulder tip defects. Ann Plast Surg 2009;63:184-7.

28. Pierce TD, Tomaino MM. Use of the pedicled latissimus muscle flap for upper-extremity reconstruction. J Am Acad of Orthop Surg 2000;8:324-31.

29. Lee KT, Mun GH. A systematic review of functional donor-site morbidity after latissimus dorsi muscle transfer. Plast Reconstr Surg 2014;134:303-14.

30. Sood A, Therattil PJ, Russo G, Lee ES. Functional latissimus dorsi transfer for upper-extremity reconstruction: a case report and review of the literature. Eplasty 2017;17:51-63.

31. Ong YS, Levin LS. Lower limb salvage in trauma. Plast Reconstr Surg 2010;125:582-8.

32. Kramers-de Quervain IA, Läuffer JM, Käch K, Trentz O, Stüssi E. Functional donor-site morbidity during level and uphill gait after a gastrocnemius or soleus muscle-flap procedure. J Bone and Joint Surg Am 2001;83-A:239-46.

33. Sugg KB, Schaub TA, Concannon MJ, Cederna PS, Brown DL. The reverse superficial sural artery flap revisited for complex lower extremity and foot reconstruction. Plast Reconstr Surg Glob Open 2015;3:1-9.

34. Pu LL. Further experience with the medial hemisoleus muscle flap for soft-tissue coverage of a tibial wound in the distal third of the leg. Plast Reconstr Surg 2008;121:2024-8.

35. Follmar KE, Baccarani A, Baumeister SP, Levin LS, Erdmann D. The distally based sural flap. Plast Reconstr Surg 2007;119:58-62.

36. Yazar S, Lin CH, Lin YT, Ulusal AE, Wei FC. Outcome comparison between free muscle and free fasciocutaneous flaps for reconstruction of distal third and ankle traumatic open tibial fractures. Plast Reconstr Surg 2006;117:2468-75.

37. Derderian CA, Olivier WAM, Baux G, Levine J, Gurtner GC. Microvascular free-tissue transfer for traumatic defects of the upper extremity: a 25-year experience. J Reconstr Microsurg 2003;19:455-62.

38. Wang HT, Fletcher JW, Erdmann D, Levin LS. Use of the anterolateral thigh free flap for upper-extremity reconstruction. J Hand Surg 2005;30:859-64.

39. Yildirim S, Avci G, Aköz T. Soft-tissue reconstruction using a free anterolateral thigh flap: experience with 28 patients. Ann Plast Surg 2003;51:37-44.

40. Kimura N, Satoh K, Hasumi T, Ostuka T. Clinical application of the free thin anterolateral thigh flap in 31 consecutive patients. Plast Reconstr Surg 2001;108:1197-208.

41. Meyer A, Horch RE, Schoengart E, Beier JP, Taeger CD, et al. Results of combined vascular reconstruction by means of AV loops and free flap transfer in patients with soft tissue defects. J Plast Reconstr Aesthet Surg 2016;69:545-53.

42. Chan JK, Harry L, Williams G, Nanchahal J. Soft tissue reconstruction of open fractures of the lower limb: muscle versus fasciocutaneous flaps. Plast Reconstr Surg 2012;130:284-95e.

43. Stranix JT, Lee ZH, Jacoby A, Anzai L, Mirrer J, et al. Forty years of lower extremity take-backs: flap type influences salvage outcomes. Plast Reconstr Surg 2018;141:1282-7.

44. Sabino J, Polfer E, Tintle S, Jessie E, Fleming M, et al. A decade of conflict: flap coverage options and outcomes in traumatic war-related extremity reconstruction. Plast Reconstr Surg 2015;135:895-902.

45. Cho EH, Shammas RL, Carney MJ, Weissler JM, Bauder AR, et al. Muscle versus fasciocutaneous free flaps in lower extremity traumatic reconstruction: a multicenter outcomes analysis. Plast Reconstr Surg 2018;141:191-9.

46. Godina M. Early microsurgical reconstruction of complex trauma of the extremities. Plast Reconstr Surg 1986;78:285-92.

47. Qiu E, Kurlander DE, Ghaznavi AM. Godina revisited: a systematic review of traumatic lower extremity wound reconstruction timing. J 
Plast Surg Hand Surg 2018;1-6.

48. Gabriel A, Gialich S, Kirk J, Edwards S, Beck B, et al. The Haiti earthquake: the provision of wound care for mass casualties utilizing negative-pressure wound therapy. Adv Skin Wound Care 2011;24:456-62.

49. Prasarn ML, Helfet DL, Kloen P. Management of the mangled extremity. Strategies Trauma Limb Reconstr 2012;7:57-66.

50. Pinzur MS. Outcomes-oriented amputation surgery. Plast Reconstr Surg 2011;127:241-7S. 